\title{
Potencial bioativo, antioxidante e antimicrobiano do extrato aquoso do processo de extração do óleo essencial de folhas de Croton blanchetianus Baill
}

Bioactive, antioxidant and antimicrobial potential of the aqueous extract from the Croton blanchetianus Baill leaf essential oil extraction process

\author{
E. C. de Vasconcelos ${ }^{1,2 *}$; M. J. G. Ferreira ${ }^{3}$; R. C. de S. Menezes ${ }^{3}$; C. R. Muniz \\ L. M. R. da Silva ${ }^{3}$; E. A. T. de Figueiredo ${ }^{3}$; G. M. F. de Aragão ${ }^{1}$ \\ ${ }^{\text {I}}$ Departamento de Engenharia Química e Engenharia de Alimentos, Laboratório Integrado de Engenharia Biológica, \\ Universidade Federal de Santa Catarina, 88040-900, Florianópolis-SC, Brasil \\ ${ }^{2}$ Curso de Agronomia, Instituto Federal de Ciência e Tecnologia do Ceará, 62930-000, Limoeiro do Norte-CE, \\ Brasil \\ ${ }^{3}$ Departamento de Engenharia de Alimentos, Laboratório de Microbiologia de Alimentos, Universidade Federal do \\ Ceará, 60356-000, Fortaleza-CE, Brasil \\ ${ }^{4}$ Laboratório de Bioimagem, Empresa Brasileira de Pesquisa Agropecuária-Embrapa, 60511-110, Fortaleza-CE, \\ Brasil \\ *elayne@ifce.edu.br \\ (Recebido em 13 de setembro de 2021; aceito em 17 de dezembro de 2021)
}

$\overline{\text { O Croton blanchetianus Baill, conhecido como marmeleiro, é rico em metabólitos secundários, como }}$ alcalóides e terpenos, que podem apresentar efeitos biológicos. Desta forma, este estudo teve como objetivo avaliar o potencial bioativo, antioxidante e antimicrobiano dos extratos aquosos resultantes do processo de extração do óleo essencial das folhas frescas e secas do C. blanchetianus. O óleo essencial foi extraído por hidrodestilação e posteriormente o extrato aquoso foi coletado e liofilizado, sendo submetido às análises. A determinação da Concentração Inibitória Mínima e Concentração Bactericida Mínima contra bactérias patogênicas de interesse em alimentos (Staphylococcus aureus, Listeria monocytogenes, Salmonella Enteritidis e Escherichia coli) foi realizada pelo método de microdiluição. O efeito dos extratos aquosos sobre as células bacterianas foi avaliado por imagens de microscopia eletrônica de transmissão. A avaliação da atividade antioxidante foi determinada pelo método ABTS e DPPH. O extrato aquoso das folhas frescas apresentou maiores teores de flavonoides e atividade antioxidante por ABTS em comparação com o extrato de folhas secas. Os compostos fenólicos, taninos e a atividade antioxidante pelo método DPPH não diferiram significativamente entre ambos os tipos de folhas. Ambos os extratos aquosos apresentaram atividade antimicrobiana apenas sobre as bactérias Gram-positivas (S. aureus e L. monocytogenes). Foram observadas alterações celulares em $S$. aureus e L. monocytogenes sob ação do extrato aquoso de folhas frescas e secas. Os resultados indicam a possibilidade de utilização do extrato aquoso das folhas secas de C. blanchetianus como aditivo bioativo e para melhoria da segurança de alimentos, no que diz respeito às bactérias Gram-positivas.

Palavras-chave: marmeleiro, bactérias patogênicas, microscopia eletrônica de transmissão.

Croton blanchetianus Baill, known as marmeleiro, is rich in secondary metabolites, such as alkaloids and terpenes, which can have biological effects. Thus, this study aimed to evaluate the bioactive, antioxidant and antimicrobial potential of aqueous extracts, resulting of the essential oil extraction process from fresh and dry leaves of $C$. blancheticianus. The essential oil was extracted by hydrodistillation and then the aqueous extract was collected and lyophilized, being submitted to analysis. The determination of the Minimum Inhibitory Concentration and Minimum Bactericidal Concentration against pathogenic bacteria of interest in foods (Staphylococcus aureus, Listeria monocytogenes, Salmonella Enteritidis and Escherichia coli) was carried out by the microdilution method. The effect of aqueous extracts on bacterial cells was evaluated by transmission electron microscopy images. Evaluation of antioxidant activity provided by the ABTS and DPPH method. The aqueous extract from fresh leaves has higher levels of flavonoids and antioxidant activity by ABTS than the extract from dry leaves. The phenolic compounds, tannins and the antioxidant activity by the DPPH method did not differ significantly in both types of samples. Both aqueous extracts showed antimicrobial activity only against Gram-positive bacteria $(S$. aureus and L. monocytogenes). Cellular alterations were observed in S. aureus and L. monocytogenes under the action of the aqueous extract of fresh and dry leaves. The results indicate the possibility of using the 
aqueous extract of dried C. blanchtianus leaves as a bioactive additive and to improve food safety, regarding Gram-positive bacteria

Keywords: marmeleiro, pathogenic bacteria, transmission electron microscopy.

\section{INTRODUÇÃO}

A indústria de alimentos tem como uma de suas finalidades a produção de alimentos inócuos e com um prolongado tempo de vida útil. Há, portanto, uma preocupação quanto à segurança do uso de conservantes químicos, tendo em vista que são considerados responsáveis por muitos atributos carcinogênicos e teratogênicos, além da toxicidade residual [1]. O uso de conservantes químicos está na contramão da busca pelo consumo de produtos naturais e que apresentem características benéficas à saúde [2].

O Croton blanchetianus é uma espécie representativa da família Euphorbiacae, apresentando padrão de distribuição agregada nas áreas da Caatinga [3, 4]. É uma planta arbustiva, típica do sertão, encontrada em abundância no nordeste brasileiro, popularmente conhecida como marmeleiro [5]. Cascas e folhas de Croton sp. são comumente usadas na medicina popular na forma de chás e infusões para distúrbios gastrointestinais, como diarreia e constipações, dentre outros $[6,7]$.

As propriedades bioativas relacionadas ao consumo desses chás estão associadas à sua composição fitoquímica. A análise fitoquímica do extrato etanólico das folhas de $C$. blanchetianus revelou a presença de alcalóides, açúcares redutores, derivados cinâmicos, flavonóides, saponinas, taninos condensados, terpenos, esteróides, catequinas (taninos catéquicos) [8-11].

Os produtos botânicos como os óleos essenciais e os extratos de plantas medicinas e plantas silvestres têm demonstrado a presença de compostos eficazes no controle de microrganismos patogênicos [12]. Segundo Firmino et al. (2019) [13], os diterpenos metil 12-hidroxi-3,4-secocleistanta-8,11,13,15,4 (18) -pentaeno-3-oato (ICB4) e ent-ácido 3,4-secoatisa-4 (18), 16-dien-3óico (ICB8), isolados de C. blanchetianus, têm potencial para serem utilizados como agente terapêutico contra infecções causadas por estreptococos orais (Streptococcus mutans e $S$. Parasanguinis), devido à ação antibiofilme.

Os compostos bioativos relacionados à capacidade antioxidante têm sido objeto de pesquisa devido à alta importância na saúde humana [14] e uso na indústria de alimentos. Os extratos vegetais, suas misturas, concentrados e isolados têm sido constantemente estudados e revisados com relação à atividade antioxidante, como uma alternativa aos antioxidantes sintéticos $[15,16]$. A atividade antioxidante dos extratos aquosos vem contribuindo para a estabilidade de alimentos ao longo do período de estocagem [17, 18].

Desta forma, este trabalho tem como objetivo avaliar o potencial bioativo, antioxidante e antimicrobiano, do extrato aquoso resultante do processo de extração (hidrodestilação) do óleo essencial das folhas frescas e secas do marmeleiro (C. blanchetianus Baill).

\section{MATERIAL E MÉTODOS}

\subsection{Coleta e preparo das folhas de $C$. blanchetianus}

Para a coleta das folhas de $C$. blanchetianus, cinco árvores, entre as coordenadas geográficas latitude $05^{\circ} 10825^{\prime} \mathrm{S}$ e longitude $38^{\circ} 00717^{\prime} \mathrm{W}$, foram marcadas com lacres de cores diferentes na Unidade Experimental de Pesquisa e Extensão (UEPE) do Instituto Federal de Educação, Ciência e Tecnologia do Ceará (IFCE), Campus Limoeiro do Norte, cadastro no SisGen AC5ED78. A coleta foi realizada no período chuvoso, turno da manhã. Uma amostra foi coletada para a identificação e realização da exsicata e depositada no Herbário Prisco Bezerra, da Universidade Federal do Ceará (UFC) (\# 62200).

As folhas foram secas à temperatura ambiente $\left(31 \pm 1^{\circ} \mathrm{C}\right)$, durante 5 a 6 dias. As folhas frescas foram utilizadas imediatamente após coleta, para o processo de extração do óleo essencial. O teor 
de umidade das folhas frescas e secas foi determinado conforme o procedimento recomendado pelo Instituto Adolfo Lutz [19].

\subsection{Obtenção do extrato aquoso das folhas de C. blanchetianus}

O extrato aquoso foi obtido por meio da extração do óleo essencial das folhas frescas e secas do C. blanchetianus, através da técnica de hidrodestilação, em aparelho Clevenger modificado [20], acoplado a um balão de fundo redondo de $5 \mathrm{~L}$ e uma manta térmica como fonte geradora de calor, conforme modelo descrito na Farmacopeia Brasileira (2019) [21]. Para o processo de extração, ambo tipos de folhas (secas ou frescas) (300 g) foram colocadas no balão de fundo redondo com adição de água destilada $(2,5 \mathrm{~L})$ e submetidas a uma temperatura de $100{ }^{\circ} \mathrm{C}$ por 2 horas, contadas a partir do momento da condensação da primeira gota de óleo. Posteriormente ao período de extração do óleo essencial das folhas, o extrato aquoso presente no balão de fundo redondo, obtido por decocção das folhas foi filtrado, coletado em frasco de cor âmbar e denominados extrato aquoso das folhas frescas (EAFF) e extrato aquoso das folhas secas (EAFS) e ambos armazenado sob refrigeração $\left(2\right.$ a $\left.8{ }^{\circ} \mathrm{C}\right)$. Em seguida, as amostras foram liofilizadas e armazenadas em frasco de vidro, protegido da luz e armazenadas a $-18^{\circ} \mathrm{C}$, até o momento das análises.

\subsection{Quantificação de compostos bioativos e determinação da atividade antioxidante}

A quantificação de compostos fenólicos nas amostras dos extratos aquosos foi realizada de acordo com Larrauri et al. (1997) [22], através do método espectrofotométrico utilizando o reagente de Folin-Ciocalteu, ácido gálico (Sigma-Aldrich, EUA) como padrão e concentração de $10 \mathrm{mg} / \mathrm{mL}$ dos EAFF e EAFS do C. blanchetianus, sendo as análises feitas em triplicata. A absorbância foi medida em espectrofotômetro (SHIMADZU, modelo UV-1800), a um comprimento de onda de $700 \mathrm{~nm}$ e os resultados dos compostos fenólicos totais foram expressos em mg equivalente de ácido gálico (EAG) por $100 \mathrm{~g}$ de extrato seco.

A determinação de taninos nas amostras EAFF e EAFS foi baseada na metodologia do IAL (2008) [19], que utiliza o ácido tânico (Sigma-Aldrich, EUA) para a curva padrão. A concentração dos extratos utilizada foi de $4 \mathrm{mg} / \mathrm{mL}$. As análises foram realizadas em triplicata, a leitura foi feita num espectrofotômetro (SHIMADZU, modelo UV-1800) a $760 \mathrm{~nm}$, e o resultado final expresso em mg equivalente de ácido tânico (EAT)/g.

A determinação dos teores de flavonoides totais foi realizada segundo o método descrito por Woisky e Salatino (1998) [23], utilizando uma curva padrão de quercetina (Sigma, EUA) e a concentração dos extratos aquosos testada foi de $4 \mathrm{mg} / \mathrm{mL}$, sendo utilizadas alíquotas de $0,1 \mathrm{~mL}$ e $0,2 \mathrm{~mL}$ das amostras EAFF e EAFS, respectivamente. As análises foram realizadas em triplicata e a leitura em espectrofotômetro a $420 \mathrm{~nm}$, sendo os resultados expressos em $\mathrm{mg}$ de quercetina por $100 \mathrm{~g}$ de EAFF e EAFF do C. blanchetianus.

A capacidade antioxidante do EAFF e EAFS do C. blanchetianus foi determinada pelo método de captura do radical 2,2-difenil-1-picril-hidrazil (DPPH), de acordo com metodologia descrita por Rufino et al. (2007) [24]. Para a realização do ensaio, as amostras foram diluídas em água destilada nas concentrações de 0,5, 1,0 e 2,0 mg/mL. As leituras foram realizadas através de um espectrofotômetro a $515 \mathrm{~nm}$. Os ensaios foram realizados em triplicata, e a capacidade antioxidante foi expressa como a concentração de antioxidante necessária para reduzir a quantidade original de radicais livres em $50 \%\left(\mathrm{EC}_{50}\right)$.

A capacidade antioxidante dos extratos foi também avaliada pelo método ABTS $(2,2$ '-azinobis (3-etil-benzotiazolina-6-ácido sulfônico) sal diamônio), conforme procedimento descrito por Rufino et al. (2007) [25]. Para realizar a análise de ABTS, foram preparadas soluções com as concentrações de 0,5, 1,0 e 2,0 mg/mL para o EAFF e 1,2 e 2,5 mg/mL para o EAFS. Os ensaios foram realizados em triplicata, a leitura feita em espectofotômetro a $734 \mathrm{~nm}$ e os resultados expressos em micromolar equivalente de trolox por $\mathrm{g}$ de extrato seco (liofilizado) de $C$. blanchetianus ( $\mu \mathrm{M}$ trolox/g de extrato). 


\subsection{Atividade antimicrobiana}

\subsubsection{Preparo do inóculo}

Para a determinação do potencial antimicrobiano in vitro dos EAFF e EAFS do $C$. blanchetianus, foram utilizadas linhagens de referência de Staphylococcus aureus ATCC-27664, Escherichia coli ATCC-25922, Listeria monocytogenes ATCC-19115, e Salmonella Enteritidis IAL-1132.

As cepas de $S$. aureus, $S$. Enteritidis, e E. coli foram cultivadas no meio Ágar Tripticase de Soja - TSA (Difco, Sparks, USA), e as de L. monocytogenes foram cultivadas no mesmo meio de cultura, porém enriquecido com 0,1\% extrato de levedura - TSA+YE (Difco, Detroit, EUA) e todas as cepas foram incubadas a $35^{\circ} \mathrm{C} / 24 \mathrm{~h}$ em estufa tipo BOD (Biochemical Oxygen Demand, Quimis/Modelo Q316-M26). Ao término do período de incubação, colônias isoladas de cada microrganismo foram transferidas para tubos contendo $5 \mathrm{~mL}$ do caldo triptona de soja - TSB e incubadas a $35{ }^{\circ} \mathrm{C}$ por 24 horas, em estufa tipo BOD para a obtenção de uma concentração bacteriana final de aproximadamente $10^{8} \mathrm{UFC} / \mathrm{mL}$ para cada microrganismo. Essas condições foram baseadas em ensaios anteriores que determinaram o ajuste do inóculo fazendo-se diluições seriadas a fim de obter uma suspensão bacteriana de $10^{5} \mathrm{UFC} / \mathrm{mL}$, posteriormente utilizada para os ensaios da avaliação da atividade antimicrobiana.

\subsubsection{Determinação da Concentração Inibitória Mínima (CIM) e Concentração Bactericida Mínima $(C B M)$}

Para a avaliação da atividade antimicrobiana dos extratos aquosos foi utilizado o método de microdiluição, utilizando placas de 96 poços [26]. Inicialmente, os EAFF e EAFS liofilizados foram diluídos em água destilada estéril e filtrados $(0,22 \mu \mathrm{m})$. As concentrações testadas estavam no intervalo de 3 a $25 \mathrm{mg} / \mathrm{mL}$ para os ensaios de L. monocytogenes e $S$. aureus e 28 a $50 \mathrm{mg} / \mathrm{mL}$ para E. coli e $S$. Enteriditis. Em cada poço da microplaca, foram adicionados $100 \mu \mathrm{L}$ das diluições dos extratos e, em seguida, foram adicionadas alíquotas de $100 \mu \mathrm{L}$ em caldo Tripticase de Soja (TSB) contendo cada inóculo individualmente, com uma concentração final de $10^{5} \mathrm{UFC} / \mathrm{mL}$. Todos os experimentos, nas diferentes concentrações, foram realizados em triplicata. O controle positivo consistiu em $100 \mu \mathrm{L}$ do inóculo em caldo TSB e $100 \mu \mathrm{L}$ água, e o controle negativo foi elaborado com diferentes concentrações da solução de extrato aquoso testadas adicionadas de caldo TSB. A microplaca foi incubada a $35 \pm 1,0^{\circ} \mathrm{C}$ por 24 horas em leitor de absorbância onde foi realizada leitura de densidade óptica inicial (D.O.) a $630 \mathrm{~nm}$, desde o tempo zero (t0) e a cada 2 horas até o tempo de 24 horas (t24). Os resultados foram obtidos pela diferença das leituras de absorbância DO630nm (t24 - t0), sendo consideradas as Concentração Inibitória Mínima (CIM), as menores concentrações em que a solução do extrato inibiu o crescimento dos microrganismos, definido como a leitura a DO630, com diferença de leitura (t24 - t0) $\leq 0,05$ [27]. Para determinação da Concentração Bactericida Mínima (CBM), uma alíquota de $100 \mu \mathrm{L}$ de cada poço cuja concentração das soluções de extrato indicava atividade inibitória $((\mathrm{t} 24-\mathrm{t} 0) \leq 0,05)$ foi espalhada na superfície de placa contendo meio Ágar Tripticase de Soja - TSA, em seguida as placas foram incubadas a $35^{\circ} \mathrm{C}$ por 24 horas. As CBM's foram identificadas como as menores concentrações das soluções antimicrobianas de extratos testadas, cujas contagens das placas indicaram redução de três ciclos logarítmicos $(3,0 \log 10 \mathrm{UFC} / \mathrm{mL})$ de células viáveis, a partir da concentração do inóculo inicial $\left(10^{5} \mathrm{UFC} / \mathrm{mL}\right)$ ou aquelas que apresentaram a ausência de crescimento microbiano [26, 27].

\subsubsection{Observação microscópica da ação do extrato aquoso sobre os microrganismos}

O preparo das cepas de S. aureus e L. monocytogenes foi realizado conforme o item 2.4.1. Nos ensaios de microscopia eletrônica de transmissão por contraste negativo foram feitos o controle positivo e a CBM do extrato aquoso de $C$. blanchetianus para cada bactéria. 
Volumes iguais do fixador Karnovsky (glutaraldeído 2,5\% e paraformaldeído 4\% em tampão fosfato de sódio $0,1 \mathrm{M} \mathrm{pH} \mathrm{7,4)} \mathrm{e} \mathrm{da} \mathrm{suspensão} \mathrm{bacteriana} \mathrm{de} 10^{5} \mathrm{UFC} / \mathrm{mL}$ foram colocados em tubos eppendorf $(2 \mathrm{~mL})$ e mantidos a $4{ }^{\circ} \mathrm{C}$, durante a noite [28]. Posteriormente, foram realizadas quatro lavagens nas amostras, sendo a primeira com o fixador e as outras três lavagens com tampão fosfato, sempre após retirar o sobrenadante e ressuspender o precipitado. Entre cada lavagem, as amostras foram centrifugadas a $5.000 \mathrm{rpm}$ por $10 \mathrm{~min}$ a $10^{\circ} \mathrm{C}$. Foi colocado uma gota da solução microbiana sobre a grade, sendo retirado o excesso após três minutos. Em seguida, foi adicionada uma gota do contrastante ácido fosfotúngstico, deixado em repouso por três minutos e posteriormente retirado o excesso. As amostras foram visualizadas no Microscópio Eletrônico de Transmissão Vega 3 Tescan, mediante o uso do detector STEM no laboratório de Bioimagem da Embrapa Agroindústria Tropical, conforme Muniz et al. (2019) [29].

\subsection{Análise estatística}

Os resultados dos compostos bioativos e atividade antioxidante foram avaliados estatisticamente e as comparações de médias foram realizadas utilizando o teste t-Student, bilateral para amostras independentes $(\mathrm{p}<0,05)$. Todas as análises estatísticas foram realizadas com o auxílio do software Statistica 10.

\section{RESULTADO E DISCUSSÃO}

\subsection{Compostos bioativos e a atividade antioxidante}

O teor de umidade das folhas frescas foi $54,5 \pm 1,20 \%$ e, após secagem, as folhas secas apresentaram teor de umidade de 7,5 $\pm 0,10 \%$.

A Tabela 1 apresenta os resultados das análises dos compostos fenólicos, taninos, flavonoides e atividade antioxidante pelo método ABTS e DPPH do EAFF e EAFS do C. blanchetianus.

Tabela 1: Comparação da concentração de compostos fenólicos, taninos, flavonoides, ABTS e DPPH no extrato aquoso das folhas frescas (EAFF) e extrato aquoso das folhas secas (EAFS), proveninetes do processo de hidrodestilação do $\underline{\text { C. }}$ blanchetianus.

\begin{tabular}{|c|c|c|c|c|c|}
\hline $\begin{array}{l}\text { Extrato } \\
\text { aquoso }\end{array}$ & $\begin{array}{l}\text { Compostos } \\
\text { fenólicos } \\
\text { (mg EAG/g) }\end{array}$ & $\begin{array}{c}\text { Taninos } \\
(\mathrm{mg} \text { EAT/g) }\end{array}$ & $\begin{array}{l}\text { Flavonoides } \\
\text { (mg de EQ /g) }\end{array}$ & $\begin{array}{c}\text { ABTS } \\
\mu \mathrm{M} \text { trolox/g }\end{array}$ & $\begin{array}{l}\mathrm{EC}_{50} \\
\mathrm{mg} / \mathrm{L}\end{array}$ \\
\hline EAFF & $276,05 \pm 19,17^{\mathrm{a}}$ & $\begin{array}{c}236,13 \pm \\
32,25^{\mathrm{a}}\end{array}$ & $33,94 \pm 1,60^{\mathrm{a}}$ & $\begin{array}{c}906,39 \pm \\
28,27^{\mathrm{a}}\end{array}$ & $\begin{array}{r}947,67 \pm \\
35,92^{\mathrm{a}}\end{array}$ \\
\hline EAFS & $269,92 \pm 8,35^{\mathrm{a}}$ & $\begin{array}{c}186,38 \pm \\
30,37^{\mathrm{a}} \\
\end{array}$ & $27,67 \pm 0,48^{\mathrm{b}}$ & $\begin{array}{l}627,85 \pm \\
109,39^{\mathrm{b}}\end{array}$ & $\begin{array}{l}817,5 \pm \\
163,55^{\mathrm{a}}\end{array}$ \\
\hline
\end{tabular}

a,b médias seguidas pela mesma letra na mesma coluna não diferem estatisticamente pelo teste t-Student, para amostras independentes $(\mathrm{p}<0,05)$.

A análise dos extratos aquosos identificou compostos fenólicos e taninos, que também foram observados na análise fitoquímica dos extratos etanólicos e metanólicos das folhas secas de $C$. blanchetianus, realizada por de Silva et al. (2021) [30]. Os EAFF e EAFS do C. blanchetianus não apresentaram diferença significativamente $(\mathrm{p}<0,05)$ nos teores de compostos fenólicos e taninos.

Costa et al. (2017) [31] encontraram, para o extrato etanólico do caule de Croton argyrophyllus, valores de $269,72 \pm 6,25 \mathrm{mg}$ EAG/g para o conteúdo de fenóis totais, valores próximos ao observados neste estudo. Nascimento et al. (2017) [32] observaram o potencial terapêutico dos compostos fracionados, como O-glicosídeos Kaempferol e quercetina, flavonóides-C-glicosídeos, taninos e derivados do ácido cinâmico do Croton cajucara, sobre o edema de pata em ratos induzido por carragenina, confirmando assim o uso popular deste Croton 
e atribuíram esse resultado aos compostos fenólicos que são amplamente associados a muitas atividades biológicas e farmacológicas das plantas.

A presença de taninos no extrato aquoso das folhas $C$. blanchetianus está de acordo com a prospecção fitoquímica realizada com os extratos etanólicos das folhas de C. blanchetianus, onde foi identificada a presença de taninos [33] indicando assim o bom desempenho do solvente aquoso utilizado nesse estudo. Em uma abordagem das interações ecológicas entre vegetais e herbívoros, sugere-se que os teores de taninos podem diminuir a taxa de predação por tornarem os materiais vegetais impalatáveis, afastando seus predadores naturais e constituindo assim um modo de defesa [34, 35]. Segundo da Silva et al. (2019) [36], os taninos estão entre os compostos fenólicos presentes nos extratos vegetais que apresentam atividade antioxidante.

Em relação ao teor de flavonoides, EAFF e EAFS apresentaram diferença significativa $(\mathrm{p}<0,05)$, sendo observada uma maior quantidade no EAFF em relação ao EAFS. O processo de secagem das folhas do C. blanchetianus pode ter influenciado o teor de flavonoides presente no EAFS. Alguns autores mencionam que as condições de temperatura e o tempo de secagem influenciam no rendimento de flavonoides [37-39]. Ainda Torres et al. (2018) [40] identificaram a temperatura como sendo um fator de seleção para a extração de diferentes categorias de flavonoides. Por meio da análise da composição fitoquímica não foi possível identificar flavonoides nos extratos etanólicos e metanólicos das folhas e raízes do C. blanchetianus [30].

$\mathrm{A}$ atividade antioxidante determinada pelo método $\mathrm{DPPH}\left(\mathrm{EC}_{50}\right)$ não apresentou diferença significativa entre os EAFF e EAFS. No entanto, pelo método ABTS, as amostras apresentaram diferença, com um teor de antioxidante maior para o EAFF quando comparado ao EAFS do $C$. blanchetianus (Tabela 1), provavelmente devido ao maior teor de umidade presente nas folhas frescas que pode ter contribuído para uma maior extração dos compostos bioativos presente nas folhas. Segundo Almeida et al. (2021) [41], a atividade antioxidante do extrato aquoso da casca de achachairu (Garcinia humilis) foi maior quando determinada pelo método ABTS. Os autores consideraram que isso pode ser devido ao maior poder de extração atribuído à polaridade do solvente aquoso enquanto, para a atividade antioxidante determinada por DPPH, não foi possível observar qualquer diferença relevante. De acordo com Rufino et al (2010) [42], o método ABTS é indicado para compostos hidrofílicos e o método DPPH pode ser utilizado tanto para compostos hidrofílicos e lipofílicos. Moure et al. (2001) [15] consideraram que a diferença entre os resultados da atividade antioxidante entre amostras pode acontecer por diversos fatores como temperatura, concentração da amostra, efeito do solvente usado na extração, método de determinação, dentre outros.

Contudo, outros tipos de extratos apresentaram melhores valores comparados a esse estudo. Assim, segundo de Aquino et al. (2017) [43], o extrato etanólico das folhas frescas de $C$. blanchetinaus apresentou um $\mathrm{EC}_{50}$ de $6,5 \pm 0,5 \mathrm{mg} / \mathrm{L}$. $\mathrm{O} \mathrm{EC}_{50}$ dos extratos metanólicos das folhas secas do C. argyrophyllus e do C. heliotropiifolius foram $222 \pm 8$ e $357 \pm 4 \mathrm{mg} / \mathrm{L}$, respectivamente, pelo método DPPH [44]. A literatura apresenta relatos sobre o efeito antioxidante do extrato obtido com diferentes partes da planta, como o caule, a folha de várias espécies de Croton sp. [43-46]. Brito et al. (2018) [44] relatou que os extratos das folhas do $C$. argyrophyllus e $C$. heliotropiifolius tiveram maior teor de antioxidante quando comparado ao caule.

Os resultados mostram que não houve diferença estatística entre as concentrações dos compostos fenólicos, taninos e antioxidantes pelo método DPPH entre os EAFF e EAFS. Dentre os compostos fenólicos, contudo, apenas a concentração de flavonoides foi superior na análise do EAFF. De forma prática, o EAFS apresenta vantagem sobre o EAFF, pois as folhas, logo após serem coletadas, podem ser secas, para posterior extração do óleo essencial, sem a necessidade de se proceder à imediata extração e sem prejuízo das concentrações dos principais compostos bioativos. 


\subsection{Concentração Inibitória Mínima (CIM) e Concentração Bactericida Mínima (CBM)}

Os resultados das CIM e CBM dos extratos EAFF e EAFS de $C$. blanchetianus estão dispostos na Tabela 2.

Tabela 2: Concentração inibitória mínima (CIM) e concentração bactericida mínima (CBM), expressos em $\mathrm{mg} / \mathrm{mL}$, dos extratos aquosos das folhas frescas (EAFF) e secas (EAFS), proveniente do processo de extração do óleo essencial de $\underline{C}$. blanchetianus, sobre as bactérias $\underline{S}$. aureus e $\underline{L}$. monocytogenes.

\begin{tabular}{ccccc}
\hline \multirow{2}{*}{ Extrato aquoso } & \multicolumn{3}{c}{ S. aureus } & L. monocytogenes \\
\cline { 2 - 5 } & CIM & CBM & CIM & CBM \\
\hline EAFF & 3 & 11 & 3 & NO \\
EAFS & 10 & 19 & 17 & 23 \\
\hline
\end{tabular}

NO - Não observado na faixa das concentrações estudadas

O EAFF apresentou melhor ação para as bactérias Gram-positivas, comparado ao EAFS, uma vez que apresentou ação inibitória em concentrações menores. Em relação aos microrganismos Gram-negativos (S. enteritidis e E. coli), resultados não apresentados na Tabela, os extratos aquosos de ambas as folhas não apresentaram atividade inibitória ou bactericida nas concentrações testadas. É importante ressaltar que outros estudos já mostraram que os microrganismos Gram-positivos são mais suscetíveis à ação antimicrobiana de extratos vegetais [47, 48], o que corrobora com os resultados encontrados neste estudo. Ferreira et al. (2020) [49], trabalhando com o extrato aquoso do caule do marmeleiro (C. blanchetianus), reportaram a atividade inibitória e bactericida para bactérias Gram positivas (L. monocytogenes e $S$. aureus) e Gram-negativas ( $S$. Enteritidis, E. coli e $P$. aeruginosa), sendo que as concentrações bactericidas para Gram-positivos variaram de 0,5-3 mg/mL e Gram-negativas de 4,3-19 mg/mL. A ação observada no "extrato aquoso do caule" não foi observada em relação ao "extrato aquoso de folhas" para as bactérias Gram-negativas estudadas. Trabalhando com extrato aquoso do $C$. nepetaefolius, Ferreira et al. (2020) [49] apresentaram uma CIM de $14 \mathrm{mg} / \mathrm{mL}$ para $L$. monocytogenes e ausência da CBM na faixa estudada (1 a $18 \mathrm{mg} / \mathrm{mL})$, no entanto, no presente estudo, foi encontrada uma CBM de $23 \mathrm{mg} / \mathrm{mL}$ para o EAFS.

Fennell et al. (2004) [50] ressaltaram que diversos fatores podem interferir nos diferentes valores de CIM e de CBM de extratos de plantas, como a técnica aplicada, a cepa do microrganismo utilizada, além de fatores relacionados à planta como local de plantio, época da coleta e se os extratos foram preparados a partir de plantas frescas ou secas e a quantidade de extrato testada. Ainda, os extratos brutos de espécies vegetais podem muitas vezes apresentar ação antimicrobiana mais efetiva contra patógenos devido ao sinergismo entre os constituintes bioativos, que são extraídos pelo solvente ou método de extração empregado [51].

Numa abordagem terapêutica, o uso de extratos aquosos, associados de forma sinérgica à antibioticoterapia, pode ser bastante promissor para tratamento de doenças bacterianas, podendo contribuir para diminuir o mecanismo de resistência bacteriana causada pelas drogas [52]. Autores relatam que, devido ao aumento da taxa de bactérias entéricas resistentes a antibióticos, o tratamento da enterite pode ser feito com fitoterápicos [53]. Ostrosky et al. (2008) [54] relataram a importância no desenvolvimento e produção de produtos farmacêuticos e cosméticos a partir de extratos vegetais com ação antimicrobiana. Assim, pesquisas com plantas conduzem a um caminho promissor e eficaz para descobertas de novos medicamentos, sendo necessária a elucidação dos componentes ativos presentes nas mesmas, bem como seus mecanismos de ação [55]. 


\subsection{Observação microscópica do efeito do extrato aquoso sobre as bactérias patogênicas}

Os efeitos da ação dos EAFF e EAFS sobre as células de $S$. aureus e do EAFS sobre a cepa de L. monocytogenes, nas concentrações equivalentes às respectivas CBM's, podem ser observadas na Figura 1.

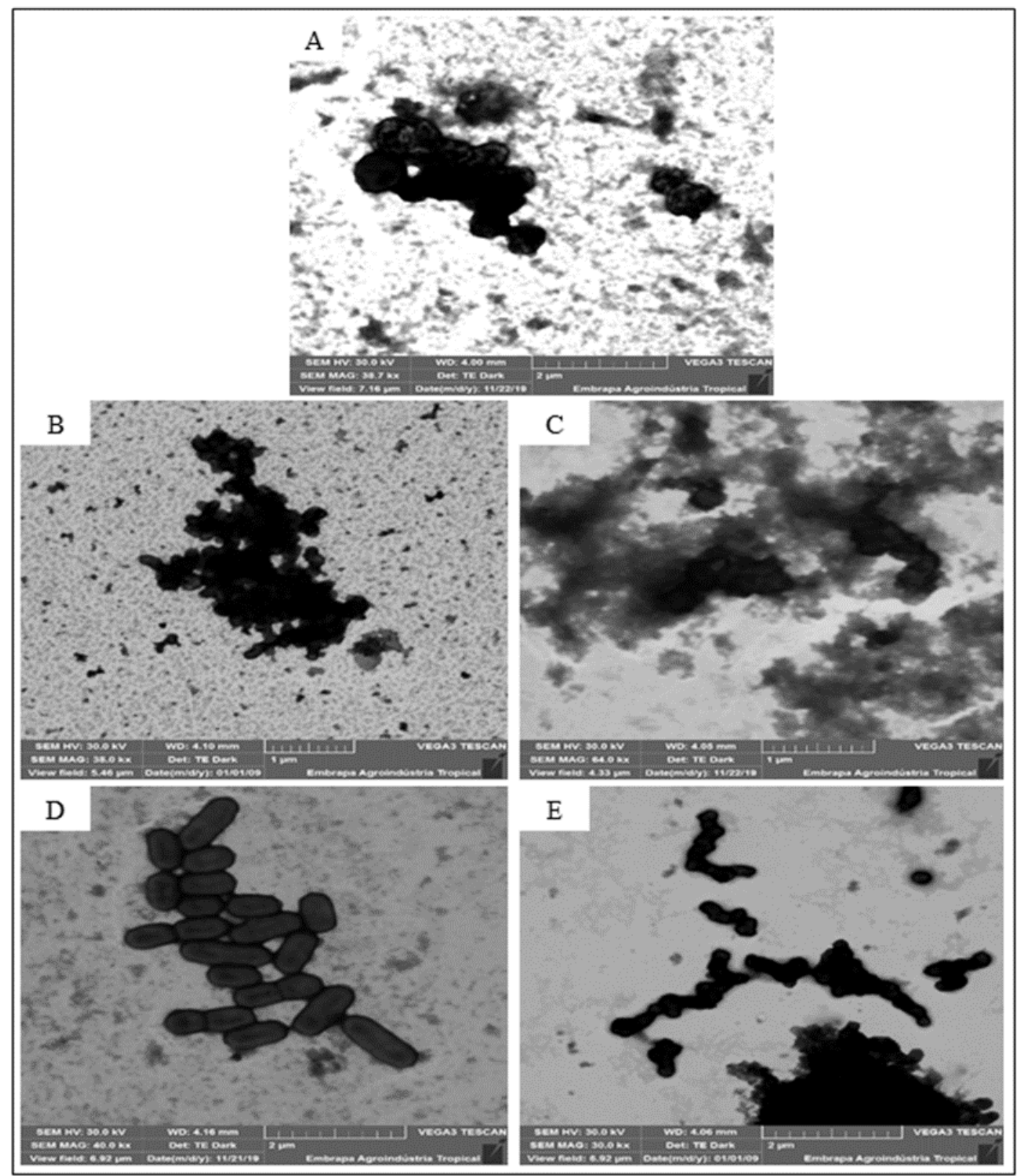

Figura 1: Imagens de microscopia eletrônica de transmissão de células de $\underline{S}$. aureus $(A-$ controle, aumento de 38.700x); sob ação do extrato aquoso de $\underline{C}$. blanchetinaus proveniente das folhas frescas $(B$, aumento de 38.000x) e folhas secas (C, aumento de 64.000x) e de células de $\underline{L}$. monocytogenes $(D-$ controle, aumento de 40.000x) sob efeito do extrato aquoso das folhas secas (E, aumento de 30.000x). nas concentrações equivalentes aos respectivos $C B M$ 's.

A morfologia celular foi visualizada através de microscopia eletrônica de transmissão (MET) de culturas bacterianas tratadas com EAFF e EAFS para auxiliar na compreensão da ação antimicrobiana dos extratos aquosos do C. blanchetianus. Segundo Xing et al. (2009) [56], as 
observações por microscopia eletrônica são ferramentas poderosas para os pesquisadores entenderem melhor o impacto de um agente estressor na morfologia de células bacterianas.

A eletromicrografia de $S$. aureus, sem tratamento com o extrato aquoso do C. blanchetianus, mostrou células bem definidas, esféricas, arranjadas em cachos e com paredes íntegras (Figura 1A). A ação do EAFF (Figura 1B) e EAFS (Figura 1C) sobre S. aureus apresentou uma perda da limitação entre os arranjos de células bacterianas, ainda com alteração da forma de cocos para agregados celulares, sendo que, sob a ação do EAFS, houve um extravasamento acentuado do conteúdo celular e ausência da forma original, possivelmente devido à presença de compostos bioativos.

Nos tratamentos utilizando-se a CBM do EAFS do $C$. blanchetianus sobre as culturas bacterianas de L. monocytogenes, as imagens (Figura 1) mostram uma alteração da forma da célula, possivelmente em nível de parede celular já que a mesma tem a função de manter a forma da célula, proteger contra variações da pressão osmótica e influências do meio externo [57] (Figura 1E). Foi observada uma perda da integridade celular, contrastando com o controle (Figura 1D), em que pode se visualizar uma nítida delimitação celular com formato celular típico de bastonetes e estruturas internas preservadas e nítidas. Utilizando extrato aquoso de chambá (Justicia pectoralis Jacq) contra L. monocytogenes, Guimarães et al. (2020) [58] reportaram que, mesmo altas concentrações $(90-150 \mathrm{mg} / \mathrm{mL})$ não foram suficientes para destruir sua parede celular e provocar a inibição desse microrganismo.

Kim e Fung (2004) [59], estudando o efeito antibacteriano do extrato aquoso de Puerariae radix em patógenos de origem alimentar, concluíram que as células bacterianas tratadas foram mortas pela ruptura das paredes e membranas celulares, bem como por perturbações irregulares da matriz intracelular.

\section{CONCLUSÃO}

Os extratos aquosos provenientes do processo de hidrodestilação do óleo essencial do $C$. blanchetianus (marmeleiro) apresentam compostos bioativos, tanto nos extratos aquosos obtidos das folhas frescas como nos obtidos das folhas secas do C. blanchetinuus. Assim, os resultados apresentados sugerem que os extratos aquosos apresentam potencial para serem utilizados como aditivos em alimentos, agindo como conservantes e antioxidantes.

Os extratos aquosos das folhas frescas e secas de C. blanchetianus apresentaram atividade antimicrobiana sobre os microrganismos Gram-positivos ( $S$. aureus e L. monocytogenes), e ausência de atividade antimicrobiana sobre os microrganismos Gram-negativos ( $S$. Enteritidis e E. coli). A concentração bactericida mínima do extrato do C. blanchetianus provocou uma alteração na morfologia de $S$. aureus e de L. monocytogenes, sendo mais expressivo em culturas de $S$. aureus, com extravasamento celular.

As análises realizadas mostraram que é possível utilizar o extrato aquoso proveniente das folhas secas, cuja extração do óleo essencial não precisa ser imediata após a colheita, sem grandes prejuízos nos teores das substâncias bioativas, apresentando vantagem tecnológica sobre o extrato aquoso das folhas frescas.

Os resultados apontam um potencial para a melhoria da segurança de alimentos, utilizando-se compostos naturais (extratos aquosos de C. blanchetianus) que podem ser rotulados como "verdes", indo ao encontro das demandas dos consumidores por produtos mais naturais e seguros. Os resultados desse trabalho mostram o potencial no uso do extrato aquoso de $C$. blanchetianus, no entanto, é necessária a realização de algumas análises complementares, tais como teste de toxicidade e análises sensoriais para confirmar a possibilidade de utilização desse extrato em alimentos.

\section{AGRADECIMENTOS}

Os autores agradecem a Coordenação de Aperfeiçoamento de Pessoal de Nível Superior (CAPES)/Doutorado Institucional (DINTER), a Universidade Federal do Ceará (UFC), a Embrapa Agroindústria Tropical pelas imagens de microscopia. 


\section{REFERÊNCIAS BIBLIOGRÁFICAS}

1. Moreira MR, Ponce AG, Del Valle CE, Roura SI. Inhibitory parameters of essential oils to reduce a foodborne pathogen. LWT-Food Sci Technol. 2005;38:565-70. doi: 10.1016/j.lwt.2004.07.012

2. Sakurai FN, Estrela KCA, Tamayo MS, Casseb MO, Nakasato M. Caracterização das propriedades funcionais das ervas aromáticas utilizadas em um hospital especializado em cardiopneumologia. Demetra. 2016;11(4):1097-113. doi: 10.12957/demetra.2016.18170

3. Barbosa AS, de Andrade AP, Félix LP, Aquino ÍS, Silva JHCS. Composição, similaridade e estrutura do componente arbustivo arbóreo de áreas de Caatinga. Nativa. 2020 Mai/Jun;8(3):314-22. doi: 10.31413/nativa.v8i3.9494

4. de Souza MR, Ferreira MB, de Sousa GG, Alves AR, de Holanda AC. Caracterização florística e fitossociológica do componente lenhoso de um fragmento florestal de Caatinga em Serra do Mel, Rio Grande do Norte, Brasil. Nativa. 2020 Mai/Jun;8(3):329-35. doi: 10.31413/nativa.v8i3.9136

5. Maia-Silva C, da Silva CI, Hrncir M, de Queiroz RT, Imperatriz-Fonseca VL. Guia de plantas: visitadas pelas abelhas na Caatinga. 1 ed. Fortaleza (CE): Fundação Brasil Cidadão; 2012.

6. Queiroz MMF, Queiroz EF, Zeraik ML, Marti G, Favre-Godal Q, Simões-Pires C, et al. Antifungals and acetylcholinesterase inhibitors from the stem bark of Croton heliotropiifolius. Phytochem Lett. 2014. Dec;10:xxxvii-xciii. doi: 10.1016/j.phytol.2014.08.013

7. Chaves SAM, Reinhard KJ. Palespharmacology and Pollen: Theory, method and application. Mem Inst Oswaldo Cruz. 2003;98(Suppl):207-11.

8. Freitas AFS, Costa WK, Machado JCB, Ferreira MRA, Paiva PMG, Medeiros PL, et al. Toxicity assessment and antinociceptive activity of an ethanolic extract from Croton blanchetianus (Euphorbiaceae) leaves. S Afr J Bot. 2020;(133):30-9. doi: 10.1016/j.sajb.2020.06.015

9. Oliveira IMM, Santos HS, Sena Jr DM, Cruz BG, Teixeira AMR, Freire PTC, et al. Vibrational spectra and DFT calculations of sonderianin diterpene. J Mol Struct. 2015 Jun;(1099):226-31. doi: 10.1016/j.molstruc.2015.06.049

10. dos Santos PM, Scripsema J, Huster RM. Flavonóides O-glicosilados de Croton campestris St. Hill. (Euphorbiaceae). Rev Bras Farmacogn. 2005 Out/Dez;(4):321-5.

11. Lopes EL, Andrade Neto M, Silveira ER, Pessoa ODL, Braz-Filho, R. Flavonoides e sesquiterpenos de Croton pedicellatus Kunth. Quim Nova. 2012;35(11):2169-72.

12. Ootani MA, Aguiar RW, Ramos ACC, Broto DR, da Silva JB, Cajazeira JP. Use of essential oils in agriculture. J Biotechnol Biodivers. 2013 May;4(2):162-74.

13. Firmino NCS, Alexandre FSO, de Vasconcelos MA, Pinheiro AA, Arruda FVS, Guesdes MLS, et al. Diterpenes isolated from Croton blanchetianus Baill: Potential compounds in prevention and control of the oral Streptococci biofilms. Ind Crops Prod. 2019;131:371-77. doi:10.1016/j.indcrop.2019.01.062

14. Paz M, Gíllon P, Barroso MF, Carvalho AP, Domingues VF, Gomes AM, Becker H, et al. Brazilian fruit pulps as functional foods and additives: evaluation of bioactive componunds. Food Chem. 2015 Apr;1(172):462-8. doi: 10.1016/j.foodchem.2014.09.102

15. Moure A, Cruz JM, Franco D, Domínguez JM, Sineiro J, Domínguez H, et al. Natural antioxidants from residual sources. Food Chem. 2001;72:145-71.

16. Silva MLC, Costa RS, Santana AS, Bello-Koblitz MG. Compostos fenólicos, carotenóides e atividade antioxidante em produtos vegetais. Semin Cienc Agrar. $2010 \mathrm{Jul} / \mathrm{Set}$;31(3):669-82.

17. Vencato AA, Nickel VS, Silva MAS, Kindlein L, Bergmann GP, Avancini CAM. Salt and crude plant extracts as preservatives in a meat model system (ground pork shoulder). Rev Caatinga. 2020 AbrJun;33(2):562-70. doi: 10.1590/1983-21252020v33n229rc

18. Veeck APL, Klein B, Ruviaro AR, Quatrin A, Ferreira LF, Daniel AP, et al. Estabilidade lipídica de filés de carpa húngara congelados tratados com extratos Lippia alba. Cienc Rural. 2015 Jun;45(6):11139.

19. Instituto Adolfo Lutz. Métodos físico-químicos para análise de alimentos - IAL. 4. ed. São Paulo (SP): Instituto Adolfo Lutz; 2008.

20. Gottlieb OR, Magalhães MT. Modified distillation trap. Chemist Analyst. 4th ed. 1960;49:114.

21. Farmacopeia Brasileira. 6. ed. Brasília (SP): Agência Nacional de Vigilância Sanitária SAI; 2019.

22. Larrauri JÁ, Rupérez P, Saura-Calixto F. Effect of drying temperatura on the stabilitity of polyphenols and antioxidant activityof red grape pomacepeels. J Agric Food Chem. 1997 April;45(4):1390-3. doi: 10.1021/jf960282f

23. Woisky RG, Salatino A. Analysis of propolis: some parameters and procedures for chemical quality control. J Apic Res. 1998;37(2):99-105. doi: 10.1080/00218839.1998.11100961

24. Rufino MSM, Alves RE, de Brito ES, de Morais SM, Sampaio CG, Pérez-Jiménez J, et al. Metodologia cientifica: Determinação da atividade antioxidante total em frutas pela captura do radical livre DPPH. Fortaleza (CE): Embrapa Agroindústria Tropical; 2007. (Comunicado Técnico, 127). 
25. Rufino MSM, Alves RE, de Brito ES, de Morais SM, Sampaio CG, Pérez-Jiménez J, et al. Metodologia cientifica: Determinação da atividade antioxidante total em frutas pela captura do radical livre $\mathrm{ABTS}^{\circ}+$. Fortaleza (CE): Embrapa Agroindústria Tropical; 2007. (Comunicado Técnico, 128).

26. Branen JK, Davidson PM. Enhancementofnisin, lysozyme, and monolaurin antimicrobial activities by ethylenediaminetetraacetic acid and lactoferrin. Int J Food Microbiol. 2004;90:63-74. doi: 10.1016/S0168-1605(03)00172-7

27. Brandt AL, Castillo A, Harris KB, Keeton JT, Hardin MD, Taylon TM. Inhibition of Listeria monocytogenes by food antimicrobials applied singly and in combination. J Food Sci, Malden. 2010;75(9):557-63. doi: 10.1111/j.1750-3841.2010.01843.x

28. Karnovsky MJA. Formaldehyde-glutaraldehyde fixative of high osmolality for use in electron microscopy. Int J Cell Biol. 1965;27(2):137-8.

29. Muniz CR, Azevedo HMC, Rosa MF. Preparo de amostras para observação de nanoestruturas em microscópio eletrônico de varredura acoplado a detector STEM. Fortaleza (CE): Embrapa Agroindústria Tropical; 2019. (Comunicado Técnico, 248).

30. de Silva AIB, de Sá-Filho GF, de Oliveira LC, Guzen FP, Cavalcanti JRLP, Cavalcante JS. Perfil fitoquímico de extratos etanólicos e metanólicos do Croaton Blanchetianus. Rev Bras Multidiscip. 2021;24(1):134-42. doi: 10.25061/2527-2675/ReBraM/2021.v24i1.1057

31. Costa MAR, dos Santos RRC, Gualberto AS, Cunha e Silva SL. Fenólicos totais, flavonoides totais e atividade antioxidante de extratos de Croton argyrophyllus Kunth (Euphorbiaceae). Encicl Biosf Centro Científico Conhecer, Centro Científico Conhecer. 2017 Jun;14(25):687-701. doi: 10.18677/EnciBio_2017A53

32. Nascimento AM, Maria-Ferreira D, Dai Lin FT, Limura A, de Santana-Filho AP, de Wermerc MFP, et al. Phytochemical analysis and anti-inflammatory evaluation of compounds from an aqueous extract of Croton cajucara Benth. J Pharm Biomed. 2017 Aug;145:821-30. doi: 10.1016/j.jpba.2017.07.032

33. Rodrigues OG, Angélico EC, da Costa JGM, Lucena MFA, Queiroga Neto V, Silva WW. Avaliação da atividade antioxidante dos extratos botânicos de Croton Heliotrpiifolius Kunth. e Croton blanchetianus Baill: Resultados Preliminares. Agropecuária Científica no Semiárido. 2016 Jul/Set;12(3):237-41.

34. Paes JB, Morais VM, de Lima CR. Resistência das madeiras de aroeira (Myracrodruon urundeuva), Cássia (Senna siamea) e Ipê (Tabebuia impetiginosa) a fungos e cupins xilófagos, em condições de laboratório. Floresta e Ambiente. 2002 Jan/Dez;9(1):135-44.

35. João RES, Raga A. Mecanismo de defesa das plantas contra o ataque de insetos sugadores. Campinas (SP): Agência Paulista de Tecnologia dos Agronegócios - Apta; 2016. (Documento Técnico, 23).

36. da Silva AFG, Feitosa BH, Lima VT, da Silva VFB. Antioxidante activity and total phenol, flavonoid end tanin contentes of Croton floribundus and Croton urucurana. Encicl Biosf: Centro Cientifico Conhecer. 2019;16(30):11-22. doi: 10.18677/EnciBio_2019B2

37. Borgo J, Xavier CAG, Moura DJ, Richter MF, Suyenaga ES. Influência dos processos de secagem sobre o teor de flavonoides e na atividade antioxidante dos extratos de Baccharis articulata (Lam.) Pers., Asteraceae. Rev Bras Farmacogn. 2010 Jan/Mar;20(1):12-7.

38. Rababah, TM, Al-u'datt M, Alhamad M, Al-Mahasneh M, Ereifej K, Andrade J, et al. Effects of drying process on total phenolics, antioxidant activity and flavonoid contents of common Mediterranean herbs. Int J Agric Biol Eng. 2005 Apr;8(2):145-50. doi: 10.3965/j.ijabe.20150802.1496

39. Jansuma S, Charoensuo L, Jirakiattiku Y, Harakotr B. Effects of drying temperatures and times on antioxidant contents and their activities of Centella asiatica (L.) urb. leaves. Thai Science and Technology Journal (TSTJ). 2020 Dec;28(12):2261-71. doi: 10.14456/tstj.2020.179

40. Torres DS, Pereira ECV, Sampaio PA, de Souza NAC, Ferraz CAA, de Oliveira AP, et al. Influência do método extrativo no teor de flavonoides de Cnidoscolus quercifolius POHL (Euphorbiaceae) e atividade antioxidante. Quim Nova. 2018 Mai;41(7):743-7. doi: 10.21577/0100-4042.20170236

41. Almeida RLJ, Santos NC, Alves IL, André AMMCN. Evaluation of thermodynamic properties and antioxidant activities of Achachairu (Garcinia humilis) peels under drying process. Flavour Fragr J. 2021 Oct;36:213-22. doi: 10.1002/ffj.3635

42. Rufino MSM, Alves RE, de Brito ES, Pérez-Jiménez J, Saura-Calixto FD, Mancini-Filho J. Bioactive compounds and antioxidant capacities of 18 non-tradicional tropical fruits from Brazil. Food Chem. 2010 Aug;121(4):996-1002. doi: 10.1016/j.foodchem.2010.01.037

43. de Aquino VVF, da Costa JGM, Angélico EC, de Medeiros RS, de Araújo MF, Rodrigues OG. Metabólitos secundários e ação antioxidante de Croton heliotropiifolius e Croton blanchetianus. Acta Brasiliensis. 2017 Set;1(3):7-10. doi: 10.22571/Actabra13201730

44. Brito SSS, Silva F, Malheiro R, Baptista P, Pereira JA. Croton argyrophyllus Kunth and Croton heliotropiifolius Kunth: Phytochemical characterization and bioactive properties. Ind Crops Prod. 2018;113:308-15. doi: 10.1016/j.indcrop.2018.01.044 
45. Nardi GM, Felippi R, DalBó S, Siqueira-Junior JM, Arruda DC, Monache FD, et al. Anti-inflammatory and antioxidant effects of Croton celtidifolius bark. Phytomedicine. 2003 Mar;10(2-3):176-84. doi: 10.1078/094471103321659906

46. Salatino A, Salatino MLF, Negri G. Traditional uses, Chemistry and Pharmacology of Croton species (Euphorbiaceae). J Braz Chem Soc. 2007;18(1):11-33. doi: 10.1590/S0103-50532007000100002

47. Askari GA, Kahouadji A, Khedid K, Mousaddak M, Ouaffak L, Charof R, et al. Evaluation of antimicrobial activity of aqueous and ethanolic extracts of leaves of Vitis vinifera collected from different regions in Morocco. Eurasian J Agric Environ Sci. 2012;12(1):85-90.

48. Ferreira SB, Palmeira JD, de Souza J, de Almeida JM, Figueiredo MCP, Pequeno AS, et al. Avaliação da atividade antimicrobiana in vitro do extrato hidroalcoolico de Stryphnodendron adstringens (Mart.) Coville sobre isolados ambulatoriais de Staphylococcus aureus. Rev Bras Anal Clin. 2010;42(1):27-31.

49. Ferreira MJG, Dias FGB, dos Santos MS, Menezes RCS, da Silva LMR, de Figueiredo EAT. Avaliação de plantas medicinais como potenciais aditivos antimicrobianos alimentares. Res Soc Dev. 2020;9(5):114. doi: $10.33448 /$ rsd-v9i5.3295

50. Fennell CW, Lindsey KL, McGawb LJ, Sparg SG, Stafford GI, Elgorashi EE, et al. Assessing African medicinal plants for efficacy and safety: pharmacological screening and toxicology. J Ethnopharmacol. 2004;94:205-17. doi: 10.1016/j.jep.2004.05.012

51. Simonetti E, Ethur ME, Castro LC, Kauffmann C, Giacomin AC, Ledur A, et al. Avaliação da atividade antimicrobiana de extratos de Eugenia anomala e Psidium salutare (Myrtaceae) frente à Escherichia coli e Listeria monocytogenes. Rev Bras Pl Med Campinas. 2016;18(1):9-18. doi: 10.1590/1983084X/15_005

52. Almeida GD, Godoi EP, Santos EC, de Lima LRP, de Oliveira ME. Extrato aquoso de Allium sativum potencializa a ação dos antibióticos vancomicina, gentamicina e tetraciclina frente Staphylococcus aureus. Rev Cienc Farm Basica Apl. 2013;34(4):487-92.

53. Bahador N, Baserisalehi M. The effect of Quercus castaneifolia extract on pathogenic enteric bacteria. Anaerobe. 2011 Aug;17(6):358-60. doi: 10.1016/j.anaerobe.2011.07.007

54. Ostrosky EA, Mizumoto MK, Lima MEL, Kaneko TM, Nishikawa SO, Freitas BR. Métodos para avaliação da atividade antimicrobiana e determinação da concentração mínima inibitória (CMI) de plantas medicinais. Rev Bras Farmacogn. 2008 Abr/Jun;18(2):301-7.

55. Maciel MAM, Pinto AC, Veiga Jr PV, Grynberg NF, Echevarria A. Plantas medicinais: A necessidade de estudos multidisciplinares. Quim Nova. 2002;25(3):429-38.

56. Xing K, Chen XG, Kong M, Liu SC, Cha DS, Park HJ. Effect of oleoyl-chitosan nanoparticles as a novel antibacterial dispersion system on viability, membrane permeability and cell morphology of Escherichia coli and Staphylococcus aureus. Carbohydr Polym. 2009;76:17-22. doi: 10.1016/j.carbpol.2008.09.016

57. Junqueira LC, Carneiro J. Biologia celular e molecular. 9. ed. Rio de Janeiro (RJ): Guanabara Koogan; 2012.

58. Guimarães TLF, da Silva LMR, Lima CBL, Magalhães FEA, de Figueiredo EAT. Antimicrobial activity of microcapsules with aqueous extract of chambá (Justicia pectoralis Jacq). Rev Cienc Agron. 2020;51(3):1-8. doi: 10.5935/1806-6690.20200033

59. Kim S, Fung DYC. Antibacterial effect of crude water-soluble arrowroot (Puerariae radix) tea extracts on food-borne pathogens in liquid medium. Lett Appl Microbiol. 2004;39:319-25. doi: 10.1111/j.1472765X.2004.01582.x 